\title{
'Agricultural' animals still need a protocol in this case
}

T echnically, these animals are not actually encompassed in the Animal Welfare Act definition of animals used for agricultural research. The animals in the protocol described are being used to train students, not for the direct benefit of or research to support agriculture. For animal welfare and the integrity of all animal care and use at Great Eastern University, these animals should be treated as if they were in any research project.

Questions raised include: Is Gooding resistant to writing an IACUC protocol because it takes too much time to write and then monitor the animals (e.g. individual health records)? Does he not want to provide care because these animals are considered to be "livestock"? Does he wish to avoid the use of anesthesia/analgesia because "normal agricultural practices" don't use them? Does he want to avoid monitoring because they won't follow standards of care (cleanliness, analgesics, handling) supported by typical veterinary practice or the American Veterinary Medical Association (AVMA)?
Unless Dr. Gooding is a licensed and practicing large animal veterinarian, he does not know standard practices. Perhaps Gooding should document that the techniques he will use are "industry standards" and that the animals will go on to be "used or intended for use as food or fiber, or livestock or poultry used or intended for use for improving animal nutrition, breeding, management, or production efficiency, or for improving the quality of food or fiber." If he is not a licensed, practicing veterinarian and he cannot guarantee the subsequent use of the animals, then he should be happy to write an IACUC protocol and have Great Eastern staff assist. I would also ask about Dr. Gooding's own training to determine if it was adequate to teach students in the most recent and humane methods of animal care.

Resistance to protocol writing for "farm" animals is an example of how agricultural animals are viewed as different from other animals. Because the lines are no longer clear, the same animals Gooding uses for this training may be used for research or may be sent home as a pet. AVMA Guidelines for Swine Castration ${ }^{1}$ even state "consumers are not generally aware that pigs are castrated (without anesthesia)... When informed, consumers view surgical castration without anesthesia as a serious animal welfare concern." We are all becoming more aware of humane treatment and use of farm species and that such care improves their lives and our food supply.

Great Eastern should require Gooding to submit an IACUC protocol providing details of his procedures that scientifically justifies his methods.

Mary E. P. Goad

Alopexx Enterprises, Concord, Massachusetts, USA. e-mail:mepgoad@gmail.com

Published online: 19 June 2019

https://doi.org/10.1038/s41684-019-0329-3

References

1. AVMA Guidelines for Swine Castration, https://www.avma.org/ $\mathrm{KB} /$ Resources/LiteratureReviews/Documents/swine_castration bgnd.pdf 